\title{
Rosetting of Lisianthus Cultivars Exposed to High Temperature
}

\author{
Brent K. Harbaugh \\ Gulf Coast Research and Education Center, University of Florida, 5007 \\ 60th Street East, Bradenton, FL 34203 \\ Mark S. Roh and Roger H. Lawson \\ U. S. Department of Agriculture, Agricultural Research Service, Florist \\ and Nursery Crops Laboratory, Beltsville, MD 20705
}

\section{Brent Pemberton \\ Texas A\&M Agriculture Research and Extension Center, Over-ton, $7 X 75684$}

Additional index words. Eustoma grandiflorum, flowering

\begin{abstract}
Three lisianthus [Eustoma grandiflorum (Raf.) Shinn.] cultivars 0, 10, 17, 24, or 31 days from sowing were grown in $28 \mathrm{C}$ soil for $0,7,14,21$, or 28 days to determine the effects of high temperature during seedling growth on the development of rosetted plants. Increasing the duration of high-temperature exposure increased the percentage of rosetted plants for all cultivars. Such exposure for 28 days resulted in $96 \%, 93 \%$, and $18 \%$ rosetted plants for cultivars Yodel White, Yodel Pink, and GCREC Blue, respectively. Seedling age did not affect percentage of flowering 'Yodel Pink' plants, but as seedling age increased to 31 days, the percentage of flowering plants increased with 'GCREC-Blue' and decreased for 'Yodel White'. In a second experiment, four lisianthus cultivars were grown at $22 \mathrm{C}$ for 3 weeks and then exposed for 28 days to soil at $22,25,28$, or $31 \mathrm{C}$. Increasing soil temperature resulted in more rosetted plants for all cultivars. With soil at 31C, $83 \%, 58 \%, 19 \%$, and $2 \%$ of the seedlings rosetted for the cultivars USDA-Pink, Yodel White, Little Belle Blue, and GCREC-Blue, respectively.
\end{abstract}

One factor limiting lisianthus production is the high percentage of plants that rosette and fail to flower within an acceptable cropping period $(\approx 140$ days). Lisianthus is described as an annual or biennial plant (Bailey and Baily, 1976). Rosette plants have a basal cluster of leaves and very short internodes, similar to the first season's growth of many biennials. Many rosetted seedlings have been observed in native stands of lisianthus in Grimes County, Texas (lat. $30^{\circ} \mathrm{N}$ ), during August and September when day temperatures frequently exceeded 35C. Lisianthus cultivars seeded May through October that form rosettes typically will not flower until April or May of the following year (Harbaugh, 1988). One or more side shoots of rosetted plants may elongate and flower. These semirosetted plants flower unpredictably and are of poor quality as cut flowers and potted plants.

As part of a national cooperative research project to study flowering in lisianthus, seeds were sown in February, June, and September in Bradenton, Fla. (lat. 27.5 ${ }^{\circ} \mathrm{N}$ ); Overton, Texas (lat. $32^{\circ} \mathrm{N}$ ); and Beltsville, Md. (lat.

Received for publication 31 Oct. 1991. Accepted for publication 11 Mar. 1992. Florida Agr. Expt. Sta. J. Ser. no. R-01971. Appreciation is\&tended to Sakata Seed Co.. Yokohama. Japan. for supplying lisianthus seeds. The cost bf publishing this paper was defrayed in part by the payment of page charges. Under postal regulations, this paper therefore must be hereby marked advertisement solely to indicate this fact. $\left.39^{\circ} \mathrm{N}\right)$. Depending on cultivar, we observed that from $30 \%$ to $85 \%$ of the plants rosetted for the June seeding date in all three locations. Fewer than $5 \%$ of the February or September sown plants rosetted (unpublished data). Average greenhouse temperatures exceeded $28 \mathrm{C}$ at the three locations during production of plants from June sowings. These and other observations indicated that high temperatures during seedling production may cause or contribute to rosetting in some lisianthus cultivars.

Information on the effects of temperature on lisianthus growth and development are sparse. Halevy and Kofranek (1984) reported that plants flowered 11 to 23 days earlier at 26 to $30 / 18 \mathrm{C}$ (day/night) than plants grown at 20 to $24 / 13 \mathrm{C}$ (day/night). However, temperature treatments were initiated 110 days from sowing. Several reports have indicated that temperatures $>21 \mathrm{C}$ during seedling development will reduce quality of flowering plants (Roh and Lawson, 1987; Roh et al., 1989). Data on the effect of temperature on rosetting were not presented. Ohkawa et al. (1991) reported that air temperatures $>25 \mathrm{C}$ induced rosetting in ' $\mathrm{Fu}-$ kushihai' lisianthus seedlings. Hightemperature treatments for $>14$ days completely inhibited bolting. The research reported here was conducted to determine the relationship between high temperature exposure during seedling development and the incidence of rosetting in several lisianthus cultivars.
Seedling age and duration of high-ternperature exposure (Expt. 1). Seeds were sown on 9 Jan. 1989, at Bradenton. Seedlings 0, $10,17,24$, or 31 days following sowing were grown in $28 \pm 1 \mathrm{C}$ soil for $0,7,14,21$, or 28 days. Only seedlings from the control $(0$ days from sowing) were exposed to the high temperature during germination since seeds germinated in 5 to 10 days. The plants were grown in growth chambers during the high temperature exposure and cool-white fluorescent and incandescent bulbs provided a photosynthetic photon flux (PPF) of 80 $\mu \mathrm{mol} \cdot \mathrm{m}^{-2} \cdot \mathrm{s}^{-1}$ for $12 \mathrm{~h}$. Air temperature was maintained in the range of $\pm 2 \mathrm{C}$ of the soil temperature. Germination and seedling development occurred in a controlled environment room when the plants were not being subjected to high temperature. The control room was maintained at 22 to $24 \mathrm{C}$ with a $\mathrm{PPF}$ of $30 \mu \mathrm{mol} \cdot \mathrm{m}^{-2} \cdot \mathrm{s}^{-1}$ for $12 \mathrm{~h}$ from coolwhite fluorescent lamps. When the last hightemperature treatment was completed, all plants were transplanted into 0.5-liter (10$\mathrm{cm}$ diameter) pots and grown in a fan-andpad-cooled glasshouse where the air ranged from 33/15C (day/night). Shading was provided by exterior paint, and the midday $\mathrm{PPF}$ ranged from 600 to $800 \mu \mathrm{mol} \cdot \mathrm{m}^{-2} \cdot \mathrm{s}^{-1}$.

'Yodel Pink', 'Yodel White' (Sakata Seed Co., Yokohama, Japan), and 'GCREC-Blue' (a heat tolerant, semidwarf, blue selection made at the Gulf Coast Research and Education Center, Bradenton) were studied in this experiment. There were three plants per experimental unit and four replications. The percentage of plants in each experimental unit that rosetted (basal cluster of leaves with no visible stem elongation), semirosetted (basal cluster of leaves but with stem elongation or flowering from nonterminal shoots), or flowered (open flowers from the terminal shoot and the absence of a basal cluster of leaves) was recorded 172 days from seeding. Data were analyzed following arcsine transformation for data based on percentages (Little and Hills, 1975).

Temperature regression (Expt. 2). Seedlings (21 days from sowing) of cultivars Yodel White; Little Belle Blue [released from U.S. Dept. of Agriculture (USDA)-Beltsville]; USDA-Pink (a heat sensitive, semidwarf, pink selection made at the USDA-Beltsville); and GCREC-Blue lisianthus were grown in 22, 25 , 28 , or $31 \pm 1 \mathrm{C}$ soil for 28 days. Environmental conditions during germination and seedling production were the same as in Expt. 1, except lights were on for $18 \mathrm{~h}$. After the temperature treatments, seedlings were transplanted into $3.5 \times 3.5 \times 6$-cm pyramidal cell transplant flats ( $35 \mathrm{ml}$ soil per cell). Continued development occurred under greenhouse conditions as in Expt. 1, except daylength was extended from twilight to 0200 $\mathrm{HR}$ with $2 \mu \mathrm{mol} \cdot \mathrm{m}^{-2} \cdot \mathrm{s}^{-1}$ of incandescent illumination.

The experiment was terminated 110 days from sowing, $\approx 1$ month after the first visible flower buds were observed in all cultivars. Data on the size of seedlings at transplanting, days to visible flower buds, and percentage of plants that were rosetted, semi- 
Table 1. Percentage of rosetted, semirosetted, and flowering lisianthus 'Yodel Pink', 'Yodel White', and 'GCREC-Blue' cultivars as a result of exposing 0 to 31-day-old seedlings (from sowing) to $0,7,14,21$, or 28 days of $28 \mathrm{C}$ soil temperature.

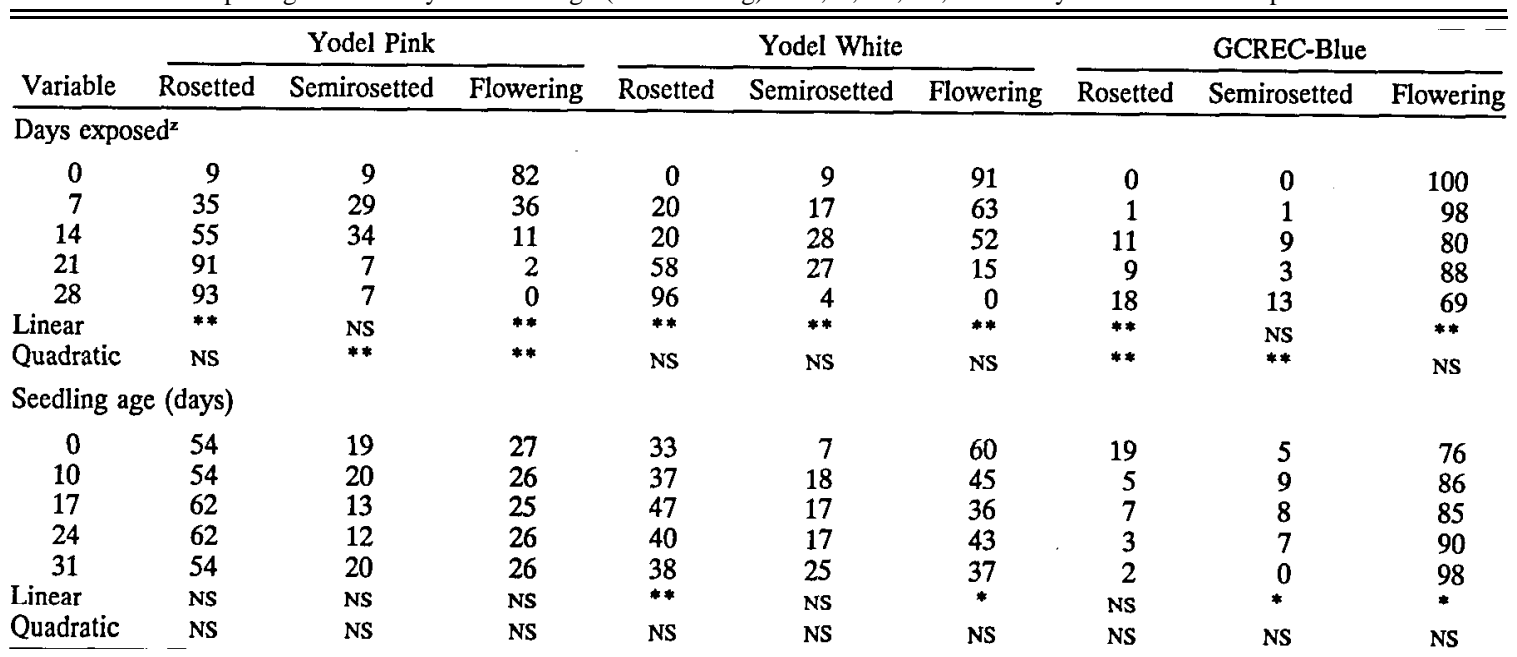

${ }^{2}$ Duration $\times$ plant age interactions were not significant. The main-effect values represent the means of 20 observations for duration treatments (four replications averaged over five seedling age treatments) and plant age (four replications averaged over five duration treatments of high temperature).

Ns,$* * *$ Nonsignificant or significant at $P=0.05$ or 0.01 , respectively.

Table 2. Growth responses of four lisianthus cultivars grown at $22 \mathrm{C}$ for 21 days from sowing and then grown in $22,25,28$, or $31 \mathrm{C}$ soils for 28 days.

\begin{tabular}{|c|c|c|c|c|c|c|}
\hline \multirow[b]{2}{*}{$\begin{array}{l}\text { Soil temp } \\
\left({ }^{\circ} \mathrm{C}\right)\end{array}$} & \multicolumn{2}{|c|}{ Flowering stage } & \multirow[b]{2}{*}{$\begin{array}{c}\text { Visible } \\
\text { bud (\%) }\end{array}$} & \multicolumn{2}{|c|}{ Seedlingy } & \multirow[b]{2}{*}{$\begin{array}{c}\text { Visible bud } \\
\text { (days) }\end{array}$} \\
\hline & $\begin{array}{c}\text { Rosette } \\
(\%)\end{array}$ & $\begin{array}{c}\text { Semirosette } \\
(\%)\end{array}$ & & $\begin{array}{l}\text { Width } \\
(\mathrm{cm})\end{array}$ & $\begin{array}{c}\text { Leaves } \\
\text { (no.) }\end{array}$ & \\
\hline \multicolumn{7}{|c|}{$U S D A-P i n k$} \\
\hline 22 & 34 & 3 & 63 & 1.6 & 6.2 & 96 \\
\hline 25 & 35 & 14 & 51 & 2.4 & 7.1 & 98 \\
\hline 28 & 65 & 8 & 27 & 3.1 & 7.3 & 102 \\
\hline 31 & 83 & 4 & 13 & 2.5 & 7.5 & 102 \\
\hline Linear & $* *$ & NS & $* *$ & $*$ & $* *$ & $\star$ \\
\hline Quadratic & NS & $*$ & NS & $* *$ & NS & NS \\
\hline \multicolumn{7}{|c|}{ Yodel White } \\
\hline 22 & 0 & 0 & 100 & 3.6 & 7.2 & 87 \\
\hline 25 & 5 & 4 & 91 & 3.9 & 7.2 & 92 \\
\hline 28 & 20 & 24 & 56 & 5.9 & 7.6 & 94 \\
\hline 31 & 58 & 16 & 26 & 4.3 & 7.4 & 100 \\
\hline Linear & $* *$ & $*$ & $* *$ & NS & NS & $* *$ \\
\hline Quadratic & NS & NS & NS & NS & NS & $* *$ \\
\hline \multicolumn{7}{|c|}{ Little Belle Blue } \\
\hline 22 & 1 & 1 & 98 & 2.8 & 7.3 & 86 \\
\hline 25 & 5 & 1 & 94 & 3.5 & 7.6 & 87 \\
\hline 28 & 3 & 3 & 94 & 4.3 & 8.4 & 88 \\
\hline 31 & 19 & 25 & 56 & 3.8 & 7.9 & 92 \\
\hline Linear & $*$ & NS & $* *$ & $*$ & $*$ & $*$ \\
\hline Quadratic & NS & NS & $*$ & NS & NS & NS \\
\hline \multicolumn{7}{|c|}{ GCREC-Blue } \\
\hline 22 & 0 & 0 & 100 & 2.0 & 6.0 & 92 \\
\hline 25 & 0 & 0 & 100 & 2.8 & 6.5 & 91 \\
\hline 28 & 0 & 0 & 100 & 3.3 & 7.2 & 91 \\
\hline 31 & 2 & 1 & 97 & 3.1 & 7.1 & 94 \\
\hline Linear & NS & NS & $*$ & NS & NS & NS \\
\hline Quadratic & NS & NS & NS & NS & NS & NS \\
\hline
\end{tabular}

${ }^{\mathrm{z}}$ Values for seedling width, leaves, and days to visible bud represent the mean of 64 observations (four replications of 16-plant experimental units). Percentage values represent the mean of four replications for percentage of 16-plant experimental units which were rosette, semirosette, or flowering.

${ }^{y}$ Data recorded after temperature treatments, 64 days from seeding.

ss, $*, * *$, Nonsignificant or significant at $P=0.05$ or 0.01 , respectively.

rosetted, or had visible buds by day (110) were recorded. The arcsine transformation was used for regression analyses of percentage data. There were 16 plants per experimental unit and four replications in time for temperature treatments. Seeds for the first two replications were sown 16 Jan. and for the two remaining replications 18 Feb. 1990.

Experiment. 1. Interactive effects between duration of high temperature exposure and plant age were not significant, so only main effects are presented and discussed. Increas- ing the duration of $28 \mathrm{C}$ exposure increased the percentage of rosetted plants for all cultivars (Table 1). However, the relative percentage of rosetted plants resulting from high temperature exposure was different for each cultivar. 'Yodel White' had 96\% rosetted plants after seedlings were exposed to high temperature for 28 days, while 'Yodel Pink had $93 \%$ and 'GCREC-Blue' had $18 \%$. The percentage of semirosetted 'Yodel Pink' plants increased as the duration of high temperature exposure increased from 0 to 14 days. In 'Yodel White', the percentage of semirosetted plants increased with increased hightemperature exposure from 0 to 21 days, and in 'GCREC-Blue', the percentage or semirosetted plants increased with increased high temperature exposure from 0 to 28 days. As the duration of high temperature exposure increased, the percentage of normal flowering plants decreased for all cultivars due to the combined increase in rosetted and semirosetted plants.

Seedling age at time of high-temperature exposure did not affect the percentage of flowering 'Yodel Pink' plants (Table 1). Increasing the seedling age at the time of high temperature exposure from 0 to 31 days increased the percentage of flowering plants for 'GCREC-Blue' but decreased the percentage for 'Yodel White'.

Experiment 2. For all cultivars except 'GCREC-Blue', the percentage of rosetted plants was higher the higher the temperature, from 22 to 31C (Table 2). As in Expt. 1, 'GCREC-Blue' appeared to be less sensitive to high temperatures, with $97 \%$ flowering plants at 31C. 'USDA-Pink' was the most sensitive cultivar, with $34 \%$ rosetted plants even at 22C. 'Little Belle Blue' had < 5\% rosetted or semirosetted plants at $\leq 28 \mathrm{C}$, but $31 \mathrm{C}$ resulted in $19 \%$ rosetted and $25 \%$ semirosetted plants. 'Yodel White' had similar percentages of rosetted $(20 \%)$ and semirosetted (24\%) plants after exposure to 28C.

In general for all cultivars, as temperature 
increased to $28 \mathrm{C}$, seedling width and number of leaves increased (Table 2). The mean number of days to visible bud increased as temperature increased to $31 \mathrm{C}$. These results indicated that higher temperatures resulted in larger transplants. However, the production of larger transplants would be of little value commercially since many of the large transplants did not flower on schedule.

In summary, the results of both experiments support the hypothesis that high temperature exposure of lisianthus seedlings causes development of rosetted and semirosetted plants. The percentage of rosetted plants increased as the duration of exposure to $28 \mathrm{C}$ soil increased from 0 to 28 days and as soil temperature increased from 22 to $31 \mathrm{C}$. Cultivars varied in their sensitivity to high temperatures during the seedling stage. The pink cultivars were the most sensitive in both experiments, with $34 \%$ rosetted plants for 'USDA-Pink' at the lowest temperature of 22C. The cultivar GCREC-Blue was selected for heat tolerance from a tissue cultured line of 'Blue Poppy' at the Gulf Coast Research and Education Center. The low tendency to form rosetted plants by 'GCRECBlue' at high temperature exposure (2\% rosetted plants with $31 \mathrm{C}$ soil for 28 days) indicates that breeding efforts can reduce the high temperature sensitivity in lisianthus.

\section{Literature Cited}

Bailey, L.H. and E.Z. Baily. 1976. Hortus Third. MacMillan, New York.

Halevy, A.H. and A.M. Kofranek. 1984. Evaluation of lisianthus as a new flower crop. HortScience 19:845-847.
Harbaugh, B.K. 1988. Scheduling lisianthus (Eustoma grandiflorum) production. Gulf Coast Res. and Educ. Ctr. Res. Rpt. BRA1988-25.

Little, T.M. and F.J. Hills. 1975. Statistical methods in agricultural research. Univ. of California Press, Davis.

Ohkawa, K., A. Kano, K. Kanematsu, and M. Korenaga. 1991. Effects of air temperature and time on rosette formation in seedlings of Eustoma grandiflorum (Raf.) Shinn. Scientia Hort. 48:171-176.

Roh, M.S., A.H. Halevy, and H.F. Wins. 1989 Eustoma grandiflorum, p, 322-327. In: A.H. Halevy (ed.). Handbook of flowering. vol. VI. Crit. Rev. Plant Sci. Nutr. Press, Boca Raton, Fla.

Roh, M.S. and R.H. Lawson. 1987. Research and development on new crops in the United States Department of Agriculture. Acta Hort. 205:3948

\title{
Role of Self-pollination and Reciprocal Stigma/Anthers Position on Fruit Set of Eight Self-compatible Almonds
}

\author{
A. Godini, L. de Palma, and M. Palasciano \\ Istituto di Coltivazioni Arboree, Università di Bari, 70126 Bari, Italy \\ Additional index words. Amygdalus communis, Prunus dulcis, Apulian almonds, hand \\ self-pollination, flower morphology, self-fruitfulness
}

\begin{abstract}
A bstract. A study to ascertain the highest possible fruit set following self-pollination of eight self-compatible cultivars of almond (A mygdalus communis $L$. = P runus dulcis $M$ ill) was carried out in Apulia (southern Italy). F ruits set from daily hand-selling were high, compared to those from unassisted self-pollination. The results support growing most of the self-compatible A pulian almonds in solid blocks, without need for cross-pollination, provided that self-pollination is optimized by insect vectors. The relative capability of the cultivars to set fruits by unassisted self-pollination was independent of the reciprocal stigma/anthers position within the same flower.
\end{abstract}

About 30 sweet and bitter almond cultivars native to Apulia (southern Italy) have been identified as self-compatible. Their fruit set after natural self-pollination averaged $<15 \%$ and never $>26 \%$ (Godini, 1977b; Godini et al., 1990a; Reina et al., 1985). Since $25 \%$ to $40 \%$ fruit set is considered optimal for almond, depending on the bloom density of the cultivar (Kester and Griggs, 1959a), the fruitfulness of Apulian self-compatible almonds by natural self-pollination is biologically interesting but horticulturally inadequate.

Two studies on the effect of natural and

Received for publication 8 July 1991, Accepted for publication 18 Feb. 1992. Research funded by the Ministero Agricoltura e Foreste (Italy), special Grant ISMEZ (Paper no. 386). We are grateful to V. D'Alessandro and P. Simeone for their invaluable cooperation in field trials. The cost of publishing this paper was defrayed in part by the payment of page charges. Under postal regulations, this paper therefore must be hereby marked advertisement solely to indicate this fact. artificial selfing on the fruit set of single selfcompatible almond cultivars have been completed. The first study, undertaken in Greece, demonstrated the capability of the Apulian cv. Truoito (syn. "Tuono") to exceed the optimal fruit set by both artificial and natural selfing of flowers (Vasilakakis and Porlingis, 1984). These successful results have been attributed to the intimate stigma/anther contact within single 'Truoito' flowers, which facilitates the natural transfer of pollen grains to the stigmatic surface. The second study was conducted in the United States on 'Le Grand, derived from peach-almond interspecific hybridization and possessing a flower morphology similar to that of 'Truoito' (Weinbaum, 1985). 'Le Grand' was incap able of achieving optimal fruit set using either artificial and natural selfing of flowers.

Given the different results of the above studies and the few genotypes concerned, further documentation involving a wider range of self-compatible almond cultivars seemed necessary. Therefore, we conducted a study to determine if self-pollination may allow selffruitful almond cultivars to bear sufficient crops to be planted in solid blocks i) without provision for cross-pollination (Kester and Asay, 1975) and/or ii) without insect vectors (Weinbaum, 1985). To answer these questions, the capability of eight Apulian selfcompatible almond cultivars to reach optimal fruit set after artificial and natural self-pollination was tested in 1990 at Valenzano (Apulia, Italy).

Cross-pollination was prevented by covering single mature trees throughout bloom with insect-proof cheesecloth cages, thus eliminating any possible injury to flowers by branch-bagging (Grasselly and Olivier, 1976). A single tree was chosen for each cultivar. On each tree, 20 flowering branches, each bearing 80 to 120 blossoms, were divided

Table 1. Bloom date and duration, number of hand self-pollinations, and weather conditions throughout the pollination period of Apulian almonds.

\begin{tabular}{|c|c|c|c|c|c|c|}
\hline \multirow[b]{2}{*}{ Cultivar } & \multicolumn{2}{|c|}{ Bloom } & \multirow{2}{*}{$\begin{array}{l}\text { Hand self- } \\
\text { pollination } \\
\text { (no.) }\end{array}$} & \multirow{2}{*}{$\begin{array}{l}\text { Mean daily } \\
\text { air temp } \\
\left({ }^{\circ} \mathrm{C}\right)\end{array}$} & \multirow[b]{2}{*}{$\begin{array}{c}\text { Rainfall } \\
\text { (mm) }\end{array}$} & \multirow{2}{*}{$\begin{array}{l}\text { Avg wind } \\
\text { speed } \\
\left(\mathrm{m} \cdot \mathrm{s}^{-1}\right)\end{array}$} \\
\hline & Date & $\begin{array}{c}\text { Duration } \\
\text { (days) }\end{array}$ & & & & \\
\hline Sannicandro & $6-21 \mathrm{Feb}$ & 16 & 14 & 10.2 & 8.4 & 1.3 \\
\hline Scorza verde & 6-24 Feb. & 19 & 17 & 10.4 & 8.4 & 1.2 \\
\hline Ferrante & 7-24 Feb. & 18 & 16 & 10.5 & 8.4 & 1.3 \\
\hline Filippo Ceo & 15-23 Fcb. & 9 & 9 & 12.0 & 0.0 & 1.0 \\
\hline Patalina & 19 Feb.-1 Mar. & 11 & 11 & 13.1 & 0.0 & 1.2 \\
\hline Tuono & 19 Feb.-1 Mar. & 11 & 11 & 13.1 & 0.0 & 1.2 \\
\hline Calò & $21-28$ Feb. & 8 & 8 & 13.0 & 0.0 & 1.0 \\
\hline Genco & 21 Feb.-1 Mar. & 9 & 9 & 13.5 & 0.0 & 1.2 \\
\hline
\end{tabular}

